\title{
Evidence-based prescribing of antibiotics for children: role of socioeconomic status and physician characteristics
}

\author{
Anita L. Kozyrskyj, Matthew E. Dahl, Dan G. Chateau, Garey B. Mazowita, Terry P. Klassen, \\ Barbara J. Law
}

§ See related article page 133

Abstract

Background: Evidence-based guidelines for antibiotic use are well established, but nonadherence to these guidelines continues. This study was undertaken to determine child, household and physician factors predictive of nonadherence to evidencebased antibiotic prescribing in children.

Methods: The prescription and health care records of 20000 Manitoba children were assessed for 2 criteria of nonadherence to evidence-based antibiotic prescribing during the period from fiscal year 1996 (April 1996 to March 1997) to fiscal year 2000: receipt of an antibiotic for a viral respiratory tract infection (VRTI) and initial use of a second-line agent for acute otitis media, pharyngitis, pneumonia, urinary tract infection or cellulitis. The likelihood of nonadherence to evidence-based prescribing, according to child demographic characteristics, physician factors (specialty and place of training) and household income, was determined from hierarchical linear modelling. Child visits were nested within physicians, and the most parsimonious model was selected at $p<0.05$.

Results: During the study period, $45 \%$ of physician visits for VRTI resulted in an antibiotic prescription, and $20 \%$ of antibiotic prescriptions were for second-line antibiotics. Relative to general practitioners, the odds ratio for antibiotic prescription for a VRTI was 0.51 (95\% confidence interval $[\mathrm{Cl}]$ 0.42-0.62) for pediatricians and $1.58(95 \% \mathrm{Cl} 1.03-2.42)$ for other specialists. The likelihood that an antibiotic would be prescribed for a VRTI was 0.99 for each successive $\$ 10000$ increase in household income. Pediatricians and other specialists were more likely than general practitioners to prescribe second-line antibiotics for initial therapy. Both criteria for nonadherence to evidence-based prescribing were $40 \%$ less likely among physicians trained in Canada or the United States than among physicians trained elsewhere.

Interpretation: The links that we identified between nonadherence to evidence-based antibiotic prescribing in children and physician specialty and location of training suggest opportunities for intervention. The independent effect of household income indicates that parents also have an important role.

CMAJ 2004;171(2):139-45
A ntibiotic resistance among children is on the rise. Over the past decade, the number of penicillinresistant Streptococcus pneumoniae infections in Canadian children grew from $2.5 \%$ to $13 \% .^{1}$ Antibiotic resistance complicates the treatment of infections and increases the risk of further illness and death. ${ }^{2}$ An association between antibiotic resistance and antibiotic use has been documented for children. Although the chain of causality is unclear, the selection of antibiotic-resistant bacteria has been promoted by multiple courses of antibiotics, long duration of antibiotic treatment, first-line treatment with broad-spectrum antibiotics and antibiotic treatment of viral respiratory tract infections (VRTIs)..$^{3-8}$ Although many of these practices are not considered as evidence-based prescribing of antibiotics, they do occur regularly. ${ }^{9-17}$

A number of Canadian and US studies have suggested that the prescription of antibiotics is influenced by physician characteristics, such as location of medical training, specialty, years in practice, hospital affiliation and type of practice (private or clinic). ${ }^{18-21}$ Parents also influence physician prescribing of an antibiotic, ${ }^{19}$ an effect that may be mediated by the socioeconomic status of parents through level of knowledge and ability to pay for the medications. ${ }^{22,23}$ Few studies have examined the influence of both household and physician factors. We undertook this study to identify the child, household and physician determinants of nonadherence to evidence-based antibiotic prescribing in a large population of children.

\section{Methods}

In this population-based study, we analyzed data for children who had physician visits for selected childhood infections from fiscal year (FY) 1996 (Apr. 1, 1996, to Mar. 31, 1997) to FY 2000. Two criteria for nonadherence to evidence-based antibiotic therapy were applied to the health care and prescription records of these children, and child, household and physician determinants of nonadherence were ascertained.

The study protocol was approved by the Human Research Ethics Board, University of Manitoba, and Manitoba's Health Information and Patient Confidentiality Committee. Data were obtained from 4 population-based electronic databases maintained 
by the Manitoba Health Services Insurance Plan (MHSIP), which provides health insurance for all Manitobans: registration files, physician reimbursement claims, hospital discharge abstracts and records of prescriptions dispensed. The MHSIP registry contains a record for every eligible individual who received insured health services, and each record includes birth date, sex and geographic location. Records of physician reimbursement for medical care are submitted under a fee-for-service arrangement and contain information on patient diagnosis according to the clinical modification of the International Classification of Diseases, 9th revision (ICD9-CM). Discharge abstracts for hospital services include information on up to 16 ICD-9-CM diagnostic codes. Prescription records submitted by retail pharmacies contain information on date of dispensing, drug name and identification number, dosage form, quantity dispensed and type of drug insurance program. Household income, which is required to calculate the incomebased deductible payment, is also captured in the prescription database. The reliability and validity of MHSIP's prescription and health care databases are high. ${ }^{24,25}$ Record linkages among databases were achieved through anonymized personal identifiers. Children were selected on the basis of age less than 19 years and the availability of data on household income.

Two measures of physicians' nonadherence to evidence-based antibiotic prescribing were evaluated: prescription of an antibiotic for a VRTI and prescription of a second-line antibiotic without prior use of a first-line agent. VRTIs were diagnoses identified from epidemiologic studies as the most likely to be of viral cause and included ICD-9-CM codes for bronchiolitis (466), bronchitis $(490,491)$, acute respiratory tract infections $(464,465)$ and the common cold (460). Acute episodes for VRTI were selected by identifying singular ambulatory physician visits for VRTI or clusters of visits, separated from each other by a period of 30 days. Antibiotic prescriptions dispensed within 7 days after a VRTI visit were defined as having been prescribed for the VRTI. When an acute episode consisted of multiple VRTI visits, the antibiotic prescription dispensed closest to the first visit was selected, and the 7-day criterion was applied to any visit within the cluster. To ensure that there were no competing conditions for which antibiotics were warranted, the VRTI visit was excluded from the analysis if there were physician visits for acute otitis media, pharyngitis, pneumonia, urinary tract infection or cellulitis between the VRTI visit and the dispensing of the antibiotic. Intervening physician visits for noninfectious diagnoses were allowed; however, if a hospital admission occurred between the VRTI visit and the dispensing of the antibiotic prescription, the VRTI visit was also excluded. These methods have been used by others to identify respiratory tract infections of viral origin. . $^{13,26,27}$

For the second criterion, the antibiotic dispensed closest to an acute episode of otitis media, pharyngitis, pneumonia, urinary tract infection, or cellulitis or impetigo (within 7 days after the episode) was selected. The definition of an acute episode was analogous to the VRTI definition. Children with more than 4 physician visits for otitis media per year (defined as having chronic otitis media) were excluded. A list of first-line antibiotics was obtained from the then-current published guidelines, which took into account usual patterns of resistance (see Appendix 1). ${ }^{28-33}$ All antibiotics that were not first-line therapy according to these guidelines were labelled as second-line agents.

Child, household and physician factors were selected on the basis of literature indicating an association with antibiotic use. ${ }^{18-23}$ Children were described by age, sex and household income. Physician characteristics included age, sex, location of training (in Canada or the United States v. elsewhere), specialty (general practitioner [GP], pediatrician or other specialist), period since licensure (less than 20 years v. 20 years or more), hospital affiliation (identified in the hospital database as the treating physician) and type of practice (solo v. group). A solo practitioner was defined on the basis of reimbursement claims received from one location with no reimbursement claims from other physicians being received from the same location. ${ }^{34}$ Physician visits and prescriptions were classified according to year and season (winter, spring, summer and fall). For the second criterion, antibiotic prescriptions were classified according to the drug insurance program that paid for the prescription: Pharmacare, Income Assistance, or self-payment or private insurance.

The odds ratio (OR) for receiving an antibiotic prescription for VRTI or for receiving a second-line antibiotic as initial therapy was determined according to child, household and physician factors. Recognizing the multilevel structure of the data, hierarchical linear modelling methods were pursued to determine the ORs. ${ }^{35}$ Child visits to a physician or prescriptions (level 1) were nested within physicians (level 2), and the most parsimonious model was selected at a significance level of $p<0.05$. Study measures were introduced into the models as continuous or binary variables. Information on household income was available in $\$ 10000$ ranges. A backward elimination process identified level 1 variables that met the significance level; these were placed into the model along with level 2 variables. The same backward elimination process was repeated to select significant level 2 variables. The final model was a population-average model that represented the average effects of each covariate across the level 2 units. Age, sex and household income were treated as random effects, and all other explanatory variables were fixed effects.

\section{Results}

\section{Antibiotics for viral respiratory tract infections}

During FY 1996 to FY 2000, 45\% of physician visits for VRTI resulted in dispensing of an antibiotic prescription. This finding is based on 21617 children with 48700 visits for VRTI to 1215 physicians. The average age was 8.5 (standard deviation 5.6) years, and there were equal numbers of male and female children. Eighty percent of the children lived in households with an annual income of less than $\$ 40000$. Physicians were predominantly male (72\%) and under 50 years of age (70\%). Over half had received training in North America, $87 \%$ were GPs, $8 \%$ were pediatricians, $6 \%$ were other specialists, and $90 \%$ had a hospital affiliation. Eighty percent had practised for less than 20 years, and $91 \%$ were in group practice.

The majority of VRTI visits were by preschool children, children living in the lowest-income households and children seen by GPs and group practitioners (Table 1 and Table 2). Most physician visits for VRTI occurred in the winter months. There were fewer VRTI visits in FY 2000 than in FY 1996. Over $50 \%$ of VRTI visits made by children to specialists other than pediatricians, solo practitioners and physicians not trained in Canada or the United States resulted in an antibiotic prescription.

The hierarchical linear modelling analysis showed that the likelihood of receiving an antibiotic prescription for 
VRTI was highest in FY 2000 and FY 1996 (Table 3). Male children, older children and those with physician visits for VRTI during the winter were the most likely to receive an antibiotic for a VRTI. Physicians aged 50 years and older were more likely than younger physicians to prescribe antibiotics for VRTI. The OR for prescription of an antibiotic for a VRTI was 0.51 (95\% CI 0.42-0.62) for pediatricians, 1.58 (95\% CI 1.03-2.42) for specialists (both relative to GPs) and 0.59 (95\% CI 0.53-0.67) for physicians trained in Canada or the United States (relative to physicians trained elsewhere). The OR for receiving an antibiotic prescription for a VRTI was 0.99 (95\% CI 0.98-0.99) for each successive $\$ 10000$ increase in household income. All ORs were independent of each other.

\begin{tabular}{|c|c|c|c|c|}
\hline \multirow[b]{2}{*}{ Characteristic } & \multicolumn{2}{|c|}{ Criterion $1^{*}$} & \multicolumn{2}{|c|}{ Criterion $2 \dagger$} \\
\hline & $\begin{array}{l}\text { No. of VRTI } \\
\text { visits }\end{array}$ & $\begin{array}{l}\% \text { of visits with } \\
\text { antibiotic } \\
\text { prescriptions }\end{array}$ & $\begin{array}{c}\text { No. of } \\
\text { antibiotic } \\
\text { prescriptions }\end{array}$ & $\begin{array}{c}\% \text { of prescriptions } \\
\text { for second-line } \\
\text { antibiotics }\end{array}$ \\
\hline \multicolumn{5}{|l|}{ Child and household } \\
\hline \multicolumn{5}{|l|}{ Patient age, yr } \\
\hline$<1$ & 2784 & 33 & 1167 & 17 \\
\hline $1-4$ & 14175 & 41 & 11462 & 22 \\
\hline $5-9$ & 14054 & 46 & 13205 & 19 \\
\hline $10-14$ & 10132 & 48 & 9224 & 18 \\
\hline$>14$ & 7555 & 52 & 6436 & 20 \\
\hline \multicolumn{5}{|l|}{ Patient sex } \\
\hline Male & 24423 & 45 & 19941 & 21 \\
\hline Female & 24277 & 45 & 21553 & 18 \\
\hline \multicolumn{5}{|l|}{$\begin{array}{l}\text { Annual household } \\
\text { income, } \$\end{array}$} \\
\hline$<30000$ & 34470 & 46 & 29330 & 20 \\
\hline $30000-59999$ & 10387 & 43 & 8944 & 19 \\
\hline $60000-89999$ & 3023 & 46 & 2453 & 16 \\
\hline$\geq 90000$ & 820 & 38 & 767 & 18 \\
\hline \multicolumn{5}{|l|}{ Visit and prescription } \\
\hline \multicolumn{5}{|l|}{ Season } \\
\hline Winter & 24740 & 46 & 19068 & 20 \\
\hline Fall & 8528 & 46 & 6697 & 18 \\
\hline Summer & 7847 & 43 & 8762 & 19 \\
\hline Spring & 7585 & 44 & 6967 & 19 \\
\hline \multicolumn{5}{|l|}{ Year } \\
\hline FY 2000 & 9087 & 47 & 8116 & 23 \\
\hline FY 1999 & 8878 & 44 & 7389 & 22 \\
\hline FY 1998 & 9481 & 45 & 7889 & 19 \\
\hline FY 1997 & 9038 & 44 & 7546 & 18 \\
\hline FY 1996 & 12216 & 46 & 10554 & 16 \\
\hline \multicolumn{5}{|l|}{ Type of infection } \\
\hline Pneumonia & & NA & 1477 & 55 \\
\hline Cellulitis or impetigo & & NA & 2534 & 25 \\
\hline Acute otitis media & & NA & 17221 & 22 \\
\hline Pharyngitis & & NA & 17633 & 15 \\
\hline Urinary tract infection & & NA & 2629 & 12 \\
\hline \multicolumn{5}{|l|}{ Prescription insurance } \\
\hline Pharmacare & & NA & 39305 & 18 \\
\hline Income assistance & & NA & 808 & 19 \\
\hline Private or self-pay & & NA & 1381 & 63 \\
\hline
\end{tabular}




\section{Use of second-line antibiotics as initial therapy}

Included in this analysis were 41494 antibiotic prescriptions dispensed to 19895 children after visits to 1259 physicians for the 5 childhood infections studied. Forty-three percent of physician visits were for pharyngitis, $42 \%$ for acute otitis media, $11 \%$ for cellulitis, impetigo or urinary tract infections, and $4 \%$ for pneumonia. Second-line agents represented 19\% $(n=8091)$ of all antibiotic prescriptions for these conditions. Nineteen percent $(n=1537)$ of secondline antibiotic prescriptions were for cefaclor, and 22\% ( $n=$ 1780) were for azithromycin and clarithromycin.

The distribution of physician characteristics was comparable to that for the VRTI analysis, but the proportion of specialists other than pediatricians was higher (9\%). The greatest number of second-line antibiotic prescriptions were received by children aged 1-9 years, children living in the lowest-income households and children seeing GPs and group practitioners (Table 1 and Table 2). Fifty-five percent of visits for pneumonia (812/1477) resulted in the prescription of second-line antibiotics, as did more than $20 \%$ of visits for cellulitis or impetigo (636/2534) and acute otitis media (3703/17 221). Second-line agents were also prescribed in more than $20 \%$ of cases for the following vari- ables: last 2 study years, child age 1-4 years, child sex male, and treatment by physicians who were specialists or not trained in Canada or the United States. The majority of antibiotic prescriptions (97\%) were reimbursed by provincial drug plans, but second-line agents accounted for 871 (63\%) of 1381 antibiotic prescriptions in the self-payment or private plan category. Over half of the latter prescriptions were for cefaclor, azithromycin or clarithromycin.

Hierarchical linear modelling findings indicated that children were $30 \%$ less likely (OR $0.72,95 \%$ CI 0.66-0.79) to receive a second-line antibiotic (without prior use of a first-line agent) in FY 1996 than in 1999 or 2000 (Table 4). The likelihood of second-line antibiotic use was highest during the winter months. Boys were more likely than girls to receive a second-line agent.

Both pediatricians and other specialists were more likely than GPs to prescribe second-line antibiotics (OR 1.27, 95\% CI 1.06-1.52 for pediatricians and OR 1.75, 95\% CI 1.20-2.55 for other specialists). Physicians with hospital privileges were almost twice as likely to prescribe a secondline antibiotic (OR 1.65, 95\% CI 1.27-2.14). The prescription of second-line agents was $40 \%$ less likely for physicians trained in Canada or the United States than for those trained elsewhere (OR 0.58, 95\% CI 0.51-0.66) and 20\%

Table 2: Nonadherence to evidence-based prescribing of antibiotics, by physician characteristics

\begin{tabular}{|c|c|c|c|c|}
\hline \multirow[b]{2}{*}{ Physician characteristic } & \multicolumn{2}{|c|}{ Criterion 1} & \multicolumn{2}{|c|}{ Criterion 2} \\
\hline & $\begin{array}{l}\text { No. of VRTI } \\
\text { visits }\end{array}$ & $\begin{array}{l}\text { \% of visits } \\
\text { with antibiotic } \\
\text { prescriptions }\end{array}$ & $\begin{array}{c}\text { No. of } \\
\text { antibiotic } \\
\text { prescriptions }\end{array}$ & $\begin{array}{c}\% \text { of prescriptions } \\
\text { for second-line } \\
\text { antibiotics }\end{array}$ \\
\hline \multicolumn{5}{|l|}{ Age, yr } \\
\hline$<50$ & 27075 & 44 & 24733 & 21 \\
\hline$\geq 50$ & 21625 & 47 & 16761 & 18 \\
\hline \multicolumn{5}{|l|}{ Sex } \\
\hline Male & 40584 & 46 & 33164 & 19 \\
\hline Female & 8116 & 40 & 8330 & 20 \\
\hline \multicolumn{5}{|l|}{ Location of training } \\
\hline Canada or United States & 23924 & 38 & 21982 & 16 \\
\hline $\begin{array}{l}\text { Outside Canada or } \\
\text { United States }\end{array}$ & 24776 & 52 & 19512 & 24 \\
\hline \multicolumn{5}{|l|}{ Specialty } \\
\hline General practitioner & 38475 & 49 & 33098 & 20 \\
\hline Pediatrician & 10046 & 33 & 7958 & 17 \\
\hline Other specialist & 179 & 51 & 438 & 24 \\
\hline \multicolumn{5}{|l|}{ Years in practice } \\
\hline$<20$ & 34469 & 46 & 30440 & 20 \\
\hline$\geq 20$ & 14231 & 43 & 11054 & 18 \\
\hline \multicolumn{5}{|l|}{ Hospital affiliation } \\
\hline Yes & 44842 & 45 & 39130 & 20 \\
\hline No & 3858 & 48 & 2364 & 11 \\
\hline \multicolumn{5}{|l|}{ Type of practice } \\
\hline Solo & 5326 & 54 & 3557 & 20 \\
\hline Group & 43374 & 44 & 37937 & 19 \\
\hline
\end{tabular}


less likely for physicians aged 50 years and older than for younger physicians (OR 0.78, 95\% CI 0.69-0.89). Secondline agents were 7 times more likely to be antibiotics not reimbursed by the provincial drug plan.

\section{Interpretation}

Clinical practice guidelines for the use of antibiotics in children are well established. ${ }^{9-12}$ Children with VRTIs who do not receive prescriptions for antibiotics do not have higher rates of bacterial infection or return visits to physicians. ${ }^{36}$ Children who receive first-line antibiotics for infections such as otitis media or pharyngitis are not more likely than those receiving second-line agents to have delayed resolution of symptoms. ${ }^{12,37}$ Despite this abundance of evidence, in our population-based study of 20000 children in the late 1990s we found that almost half of physician visits for VRTIs resulted in an antibiotic prescription, and second-line antibiotics were prescribed in $20 \%$ of visits for common childhood infections. The same extent of nonadherence to evidence-based prescribing practices has been described by others. ${ }^{15}$

Pediatricians were less likely than GPs to prescribe an antibiotic for a VRTI but more likely to prescribe secondline antibiotics for infections such as otitis media or pharyngitis. Physicians trained in Canada or the United States were less likely than those trained elsewhere to prescribe an antibiotic for a VRTI and to provide a prescrip-

Table 3: Likelihood of receiving an antibiotic prescription for a VRTI, by physician, child and household factors

\begin{tabular}{|c|c|}
\hline Factor & OR (and 95\% Cl) \\
\hline \multicolumn{2}{|l|}{ Physician } \\
\hline \multicolumn{2}{|l|}{ Age, yr } \\
\hline$\geq 50(v .<50)$ & $1.21(1.07-1.38)$ \\
\hline \multicolumn{2}{|l|}{ Location of training } \\
\hline Canada or United States (v. elsewhere) & $0.59(0.53-0.67)$ \\
\hline \multicolumn{2}{|l|}{ Specialty (v. general practitioner) } \\
\hline Pediatrician & $0.51 \quad(0.42-0.62)$ \\
\hline Other specialist & $1.58(1.03-2.42)$ \\
\hline \multicolumn{2}{|l|}{ Year of visit (v. 1996 or 2000) } \\
\hline 1997 & $0.93(0.89-0.99)$ \\
\hline 1998 & $0.94(0.89-1.00)$ \\
\hline 1999 & $0.92(0.86-0.97)$ \\
\hline \multicolumn{2}{|l|}{ Season of visit (v. winter) } \\
\hline Spring & $0.88 \quad(0.83-0.92)$ \\
\hline Summer & $0.88(0.84-0.94)$ \\
\hline Fall & $0.95(0.90-1.00)$ \\
\hline \multicolumn{2}{|l|}{ Child and household } \\
\hline Patient age (per 1-yr increase) & $1.02(1.02-1.03)$ \\
\hline \multicolumn{2}{|l|}{ Patient sex } \\
\hline Male (v. female) & $1.06(1.02-1.10)$ \\
\hline $\begin{array}{l}\text { Annual household income (per } \$ 10000 \\
\text { increase) }\end{array}$ & $0.99 \quad(0.98-0.99)$ \\
\hline
\end{tabular}

Note: $\mathrm{OR}=$ odds ratio, $\mathrm{Cl}=$ confidence interval. tion for a second-line agent. Physicians with hospital affiliations were more likely to prescribe second-line antibiotics, potentially because of increased awareness of new drugs before they are marketed. ${ }^{38}$ Our findings are consistent with some but not all of the existing literature. For example, in some Canadian centres, pediatricians are more likely than family physicians to prescribe broad-spectrum antibiotics for the treatment of otitis media, but they are also more likely to start antibiotics immediately in children with respiratory tract infections..$^{14,21}$

The winter season was associated with both an increased likelihood of antibiotic prescription for VRTIs and use of second-line agents. These findings potentially represent physician concerns over severity of the infection, although evidence indicates that respiratory tract infections in winter are more likely to be viral. ${ }^{39}$ In addition, second-line antibiotics were more likely to be antibiotics for which cost is not reimbursed by provincial drug plans. Nonreimbursement of costs for antibiotics such as azithromycin would mean that those prescriptions did not meet guidelines of the insurance plan requiring that first-line agents be prescribed first. Although some families had private drug insurance, other parents would have paid out-of-pocket for these drugs. Interestingly, the vast majority of second-line antibiotic prescriptions were reimbursed by the province, which meant that physicians reported them as meeting reimburse-

Table 4: Likelihood of receiving a second-line antibiotic for an infection, by physician, child and household factors

\begin{tabular}{lll}
\hline Factor & OR (and 95\% Cl) \\
\hline Physician & & \\
Age, yr & & \\
$\quad \geq 50(\mathrm{v} .<50)$ & 0.78 & $(0.69-0.89)$ \\
Hospital affiliation & & \\
$\quad$ Yes (v. no) & 1.65 & $(1.27-2.14)$ \\
Location of training & & \\
$\quad$ Canada or United States (v. elsewhere) & 0.58 & $(0.51-0.66)$ \\
Specialty (v. general practitioner) & & \\
$\quad$ Pediatrician & 1.27 & $(1.06-1.52)$ \\
Other specialist & 1.75 & $(1.20-2.55)$ \\
Year of visit (v. 1999 or 2000) & & \\
$\quad 1996$ & 0.72 & $(0.66-0.79)$ \\
$\quad 1997$ & 0.77 & $(0.71-0.84)$ \\
$\quad 1998$ & 0.79 & $(0.73-0.85)$ \\
Season of visit (v. winter) & & \\
$\quad$ Spring & 0.91 & $(0.85-0.98)$ \\
$\quad$ Summer & 0.88 & $(0.82-0.94)$ \\
$\quad$ Fall & 0.88 & $(0.82-0.95)$ \\
Child and household & & \\
Sex & & \\
$\quad$ Male (v. female) & 1.19 & $(1.13-1.25)$ \\
Prescription insurance & & \\
$\quad$ Private or self-pay (v. provincial & & \\
drug program) & 6.78 & $(5.69-8.08)$ \\
\hline
\end{tabular}


ment criteria, despite the fact that we found no evidence of initial use of a first-line drug.

Independent of physician factors, children in households with higher incomes were less likely to receive an antibiotic prescription for a VRTI. This was a relative effect, such that children with "middle-income" parents were also at risk of not receiving evidence-based antibiotic treatment. An association between low household income or parent education and lack of evidence-based antibiotic prescribing in children has been documented by others. ${ }^{40,41}$ Higher-income parents may be better informed about appropriate antibiotic therapy through greater access to literature on antibiotic resistance ${ }^{42}$ or may have greater flexibility in taking time off work to bring their children back to a physician if symptoms do not resolve. ${ }^{43}$ Although inability to pay has been cited as the most common reason for parents not filling antibiotic prescriptions, ${ }^{22}$ household income was not a significant determinant in receiving second-line antibiotics, which are generally more expensive than first-line agents. It may be that most parents are not familiar with the differences in types of antibiotics once they are prescribed.

We did not compare physician diagnoses of VRTI as presented on reimbursement claims with the corresponding patient medical records because viral cultures are rarely done in the community setting..$^{36}$ Instead, as others have, we relied on epidemiologic evidence to select diagnoses that were most likely to be viral and omitted VRTI episodes associated with intervening bacterial diagnoses. ${ }^{13,26,27}$ This definition excluded diagnoses that were potentially viral, such as pharyngitis or serous otitis media, but our goal was to identify infections for which the antibiotic prescribing rate should be zero. Diagnostic codes for urinary tract infection have been shown to be valid, ${ }^{44}$ but, despite excluding intervening diagnoses when identifying infections in our evaluation of use of second-line antibiotics, the possibility remains that we did not correctly classify these infections. The analysis also did not capture samples distributed by physicians, and it did not include strong predictors of antibiotic prescribing, such as physician perception of parental expectations. . $^{39,45}$

We have presented data on the determinants of antibiotic use for a large number of Manitoba children. The similarity between our population-based rates and those reported for Canadian children for a similar period (the late $1990 \mathrm{~s})^{46}$ provides some reassurance regarding extrapolation of these findings to all Canadian children. Our findings on physician specialty and location of training have direct implications for the undergraduate and postgraduate education of physicians. An intervention aimed at GPs would have the greatest impact on population use of antibiotics because the majority of child visits were to these physicians. Interventions such as academic detailing and prescriber feedback have proven successful in reducing antibiotic use, but multifaceted approaches involving parents work best. ${ }^{47}$ Our findings suggest that the socioeconomic status of parents should be a consideration when designing intervention programs.
This article has been peer reviewed.

From the Faculty of Pharmacy (Kozyrskyj), the Department of Community Health Sciences, Manitoba Centre for Health Policy, Faculty of Medicine (Kozyrskyj, Dahl, Chateau), the Department of Medical Microbiology (Law) and the Department of Pediatrics and Child Health (Kozyrskyj, Law), University of Manitoba, Winnipeg, Man.; Community and Long Term Care, Winnipeg Regional Health Authority (Mazowita), Winnipeg, Man.; the Department of Pediatrics, University of Alberta (Klassen), Edmonton, Alta.; and the Child Health Program, Capital Health Authority (Klassen), Edmonton, Alta.

Competing interests: None declared.

Contributors: Anita Kozyrskyj, Garey Mazowita, Terry Klassen and Barbara Law were responsible for the conception and design of the study. All authors contributed to the analysis and interpretation of data, participated in drafting and revising the article for important content, and approved the final version for publication.

Acknowledgements: This research was conducted using the Population Health Research Data Repository at the Manitoba Centre for Health Policy, Winnipeg. We would like to acknowledge the research support of Anita Carrie.

This study was funded by the Canadian Population Health Initiative Operating Grant Program, Canadian Institute for Health Information (CIHR). Anita Kozyrskyj is the recipient of a CIHR New Investigator Award.

\section{References}

1. Scheifele D, Halperin S, Pelletier L, Talbot J, Vaudry W, Jadavji T, et al Update on penicillin resistance rates among pneumococci causing invasive infection in children - Canada, 1998 [abstract]. Paediatr Child Health 2000;5 (Suppl A):37A

2. McCracken JH Jr. Emergence of resistant Streptococcus pneumoniae: a problem in pediatrics. Pediatr Infect Dis 7 1995;14:424-8.

3. Arason V, Kristinsson KG, Sigurdsson JA, Stefansdottir G, Molstad S, Gugmundsson $\mathrm{S}$. Do antimicrobials increase the carriage rate of penicillin resistant pneumococci in children? Cross sectional prevalence study. BM7 1996; 313:387-91.

4. Guillemot D, Carbon C, Balkau B, Geslin P, Lecoeur H, VauzelleKervroedan F, et al. Low dosage and long treatment duration of $\beta$-lactam risk factors for carriage of penicillin-resistant Streptococcus pneumoniae. FAMA 1998;279:365-70.

5. Nasrin D, Collignon PJ, Roberts L, Wilson EJ, Pilotto LS, Douglas RM. Effect of beta lactam antibiotic use in children on pneumococcal resistance to penicillin: prospective cohort study. BM7 2002;324:28-30.

6. Block SL, Harrison CJ, Hedrick JA, Tyler RD, Smith RA, Keegan E, et al Penicillin-resistant Streptococcus pneumoniae in acute otitis media: risk factors, susceptibility patterns and antimicrobial management. Pediatr Infect Dis 7 1995;14:751-9.

7. Cohen ML. Epidemiology of drug resistance: implications for a post-antimicrobial era. Science 1992;257:1050-5.

8. Seppala H, Kalukka T, Vuopio-Varkila J, Muotiala A, Helenius H, Lager K, et al. The effect of changes in the consumption of macrolide antibiotics on erythromycin resistance in group A streptococci in Finland. $N$ Engl 7 Med 1997;337:441-6.

9. Rosenstein N, Phillips WR, Gerber MA, Marcy SM, Schwartz B, Dowell SF The common cold: principles of judicious use of antimicrobial agents. Pediatrics 1998;101(Suppl): 181-4.

10. O'Brien KL, Dowell SF, Schwartz B, Marcy SM, Phillips WR, Gerber MA. Cough illness/bronchitis: principles of judicious use of antimicrobial agents. Pediatrics 1998;101(Suppl):178-81.

11. Dowell SF, Marcy SM, Phillips WR, Gerber MA, Schwartz B. Otitis media - principles of judicious use of antimicrobial agents. Pediatrics 1998; 101(Suppl):165-71

12. Kozyrskyj AL, Hildes-Ripstein GE, Longstaffe SE, Wincott JL, Sitar DS, Klassen TP, et al. Treatment of acute otitis media with a shortened course of antibiotics: a meta-analysis. FAMA 1998;279(21):1736-42.

13. Wang EE, Einarson TR, Kellner JD, Conly JM. Antibiotic prescribing for Canadian preschool children: evidence of overprescribing for viral respiratory infections. Clin Infect Dis 1999;29:155-60.

14. Pennie RA. Prospective study of antibiotic prescribing for children. Can Fam Physician 1998;44:1850-6.

15. Nyquist AC, Gonzales R, Steiner JF, Sande MA. Antibiotic prescribing for children with colds, upper respiratory tract infections, and bronchitis. $\mathcal{F} A M A$ 1998;279:875-7.

16. Arnold SR, Allen UD, Al-Zahrani M, Tan DH, Wang EE. Antibiotic prescribing by pediatricians for respiratory tract infection in children. Clin Infect Dis 1999;29(2):312-7.

17. Le Saux N, Pham B, Bjornson C, Pitters C. Antimicrobial use in febrile children diagnosed with respiratory tract illness in an emergency department. $P e-$ diatr Infect Dis 7 1999;18:1078-80. 
18. Mainous AG, Hueston WJ, Love MM. Antibiotics for colds in children. Who are the high prescribers? Arch Pediatr Adolesc Med 1998;152:349-52.

19. Watson RL, Dowell SF, Jayaraman M, Keyserling H, Kolczak M, Schwartz B. Antimicrobial use for pediatric upper respiratory infections: reported practice, actual practice, and parent beliefs. Pediatrics 1999;104(6):1251-7.

20. Berman S, Byrns PJ, Bondy J, Smith PJ, Lezotte D. Otitis media-related antibiotic prescribing patterns, outcomes, and expenditures in a pediatric Medicaid population. Pediatrics 1997;100(4):585-92.

21. Davy T, Dick PT, Munk P. Self-reported prescribing of antibiotics for children with undifferentiated acute respiratory tract infections with cough. Pediatr Infect Dis 7 1998;17:457-62.

22. Reuveni H, Sheizaf B, Elhayany A, Sherf M, Limoni Y, Scharff S, et al. The effect of drug co-payment policy on the purchase of prescription drugs for children with infections in the community. Health Policy 2002;62:1-13.

23. Bondy J, Berman S, Glazner J, Lezotte D. Direct expenditures related to otitis media diagnosis: extrapolations from a pediatric medicaid cohort. Pediatrics 2000;105:E72.

24. Kozyrskyj AL, Mustard CA. Validation of an electronic, population-based prescription database. Ann Pharmacother 1998;32:1152-7.

25. Robinson JR, Young TK, Roos LL, Gelskey DE. Estimating the burden of disease. Comparing administrative data and self-reports. Med Care 1997;35(9): 932-47.

26. McCaig LF, Besser RE, Hughes JM. Trends in antimicrobial prescribing rates for children and adolescents. 7AMA 2002;287:3096-102.

27. Mangione-Smith R, Wong L, Elliott MN, McDonald L, Stivers TJ, Roski J. Measuring the quality of antibiotic prescribing for upper respiratory infections and bronchitis in five US health plans [abstract]. Pediatric Res 2003;53:A1168.

28. Canadian Paediatric Society, Infectious Diseases and Immunization Committee. Antibiotic management of acute otitis media. Paediatr Child Health 1998;3(4):265-7. Available: www.cps.ca/english/statements/ID/id97-03.htm (accessed 2004 Apr 28).

29. Dowell SF, Butler JC, Giebink GS, Jacobs MR, Jernigan D, Musher DM, et al. Acute otitis media: management and surveillance in an era of pneumococcal resistance - a report from the Drug-resistant Streptococcus pneumoniae Therapeutic Working Group [published erratum appears in Pediatr Infect Di. 1999;18:341]. Pediatr Infect Dis 7 1999;18:1-9.

30. Fenster DL. CDC/AAP/group B streptococcal infections [letter]. Pediatrics 1998; 101:158.

31. Bisno AL, Gerber MA, Gwaltney JM Jr, Kaplan EL, Schwartz RH. Diagnosis and management of group A streptococcal pharyngitis: a practice guideline. Infectious Diseases Society of America. Clin Infect Dis 1997;25:574-83.

32. Jadavji T, Law B, Lebel MH, Kennedy WA, Gold R, Wang EE. A practical guide for the diagnosis and treatment of pediatric pneumonia. CMA7 1997; 156(5):S703-11.
33. Montgomery DF, Parks DK, Yetman RJ. Managing urinary tract infections in children. 7 Pediatr Health Care 1998;12:268-70.

34. Menec VH, Black C, Roos NP, Bogdanovic B, Reid R. Defining practice populations for primary care: methods and issues. Winnipeg: Manitoba Centre for Health Policy and Evaluation; 1999.

35. Austin PC, Goel V, van Walraven C. An introduction to multilevel regression models. Can 7 Public Health 2001;92:150-4.

36. Pichichero ME, Green JL, Francis AB, Marsocci SM, Murphy ML. Outcomes after judicious antibiotic use for respiratory tract infections seen in a private pediatric practice. Pediatrics 2000;105:753-9.

37. Schaad UB, Kellerhals P, Altwegg M. The Swiss Pharyngitis Study Group Azithromycin versus penicillin $\mathrm{V}$ for treatment of acute group A streptococcal pharyngitis. Pediatr Infect Dis 7 2002;21:304-8.

38. Jones MI, Greenfield SM, Bradley CP. Prescribing new drugs: qualitative study of influences on consultants and general practitioners. BM7 2001;323:1-7.

39. Hendley JO. Clinical virology of rhinoviruses. Adv Virus Res 1999;54:453-66.

40. Mangione-Smith R, McGlynn EA, Elliott MN, Krogstad P, Brook RH. The relationship between perceived parental expectations and pediatrician antimicrobial prescribing behaviour. Pediatrics 1999;103:711-8.

41. Thrane N, Olesen C, Schonheyder HC, Sorensen HT. Socioeconomic factors and prescription of antibiotics in 0- to 2-year-old children. 7 Antimicrob Chemother 2003;51:683-9.

42. Pichichero ME. Understanding antibiotic overuse for respiratory tract infections in children. Pediatrics 1999;104:1384-8.

43. Belongia EA, Naimi TS, Gale CM, Besser RE. Antibiotic use and upper respiratory infections: a survey of knowledge, attitudes, and experience in Wisconsin and Minnesota. Prev Med 2002;34:346-52.

44. Nicolle LE, Friesen D, Harding GK, Roos LL. Hospitalization for acute pyelonephritis in Manitoba, Canada, during the period from 1989 to 1992: impact of diabetes, pregnancy, and aboriginal origin. Clin Infect Dis 1996;22:1051-6.

45. Kumar S, Little P, Britten N. Why do general practitioners prescribe antibiotics for sore throat? Grounded theory interview study. BMF 2003;326:1-6

46. Khaled A, Ahmad F, Brogan T, Fearnley J, Graham J, MacLeod S, et al. Prescription medicine use by one million Canadian children. Paediatr Child Health 2003;8(Suppl A):43A-45A.

47. Finkelstein JA, Davis RL, Dowell SF, Metlay JP, Soumerai SB, Rifas-Shiman $\mathrm{SL}$, et al. Reducing antibiotic use in children: a randomized trial in 12 practices. Pediatrics 2001;108(1):1-7.

Correspondence to: Dr. Anita L. Kozyrskyj, Manitoba Centre for Health Policy, 408-727 McDermot Ave., Winnipeg MB R3E 3P5; fax 204 789-3910; kozyrsk@cc.umanitoba.ca

\section{Appendix 1: First-line antibiotics for selected indications}

\begin{tabular}{|c|c|c|}
\hline Infection & First-line antibiotic* & $\begin{array}{c}\text { Clinical practice guideline } \\
\text { or literature evidence }\end{array}$ \\
\hline Otitis media & $\begin{array}{l}\text { Amoxicillin, TMP-SMX, } \\
\text { erythromycin-sulfisoxazole }\end{array}$ & $\begin{array}{l}\text { Canadian Paediatric Society, }{ }^{28} \\
\text { US Centers for Disease Control and } \\
\text { Prevention }^{29}\end{array}$ \\
\hline Pharyngitis & $\begin{array}{l}\text { Penicillin V, amoxicillin, } \\
\text { erythromycin }\end{array}$ & $\begin{array}{l}\text { US Centers for Disease Control and } \\
\text { Prevention and American Academy } \\
\text { of Pediatrics, }{ }^{30} \text { Infectious Diseases } \\
\text { Society of America }\end{array}$ \\
\hline Pneumonia & Amoxicillin, erythromycin & Jadavji et $\mathrm{al}^{32}$ \\
\hline Urinary tract infection & $\begin{array}{l}\text { TMP-SMX, nitrofurantoin, } \\
\text { amoxicillin, cephalexin }\end{array}$ & Montgomery et $\mathrm{al}^{33}$ \\
\hline Cellulitis or impetigo & $\begin{array}{l}\text { Cloxacillin, erythromycin, } \\
\text { cephalexin }\end{array}$ & No practice guidelines \\
\hline
\end{tabular}

Note: TMP-SMX = trimethoprim-sulfamethoxazole.

*Antibiotics not listed here as first-line agents are considered second-line therapy. Second-line antibiotics are antibiotics suggested as alternate or possible treatments and are not considered first-line agents because of cost considerations or because of their potential to select for a broader range of antibiotic-resistant organisms. 